\title{
Progressive Collapse Potential of Existing Precast RC Beam-Column Connections - Experimental Study
}

\author{
Mohammed A. Alrubaidi and Hussein M. Elsanadedy
}

\begin{abstract}
The recent terrorist attacks around the world have prompted the respective authorities to address the risks to the critical infrastructure. Precast construction has become increasingly common in the Kingdom of Saudi Arabia because of its speed, which is extremely desirable due the current high rate of development in the Kingdom. In general, buildings are extremely vulnerable to progressive collapse if some of the columns are lost due to blast exposure. As precast buildings lack structural continuity and redundancies in the load paths, they are even more susceptible to progressive collapse than cast-in-situ monolithic buildings. Thus, to avoid catastrophic events, it is important to study the likelihood of the progressive collapse of precast structures in the Kingdom. In this study, the behavior of two different half-scale precast specimens were studied experimentally under middle column removal scenario. These specimens were designed to represent the most common types of exiting precast beam-column connections in the Kingdom of Saudi Arabia. Precast specimens were prepared with beam and column members cast individually and then assembled on test bed as is the norm in the field. One monolithic specimen, which was designed with continuous top and bottom beam reinforcement, was used as a baseline for comparison with the two precast specimens. For the three test specimens, the column removal scenario was simulated by releasing the support of the middle column and applying a high-rate loading, which involved the displacement of the test column at a rate of $100 \mathrm{~mm} / \mathrm{s}$ to failure. Behavior of different specimens was evaluated and compared on the basis of test results in terms of mode of failure and load-displacement characteristics. Test results reveal that the ultimate load carrying capacity and ductility of precast specimens are much less than that of the monolithic one. The two tested types of precast connections were found to have a very high potential of progressive collapse.
\end{abstract}

Keywords-progressive collapse, precast beam-column connection, monolithic connection

\section{Introduction}

In the last few decades, precast construction has become common in the Kingdom of Saudi Arabia because all the components of precast structures are produced in controlled

Mohammed A. Alrubaidi / Master Student

MMB Chair for Research and Studies in Strengthening and Rehabilitation of Structures, Department of Civil Engineering, King Saud University, P.O. Box 800, Riyadh 11421, Saudi Arabia,

Hussein M. Elsanadedy / Associate Professor

MMB Chair for Research and Studies in Strengthening and Rehabilitation of Structures, Department of Civil Engineering, King Saud University, P.O. Box 800, Riyadh 11421, Saudi Arabia (on leave from Helwan University, Cairo, Egypt), environment and it is being transported to the site. At site such individual components are connected appropriately. This leads to faster construction, reduced formwork and scaffolding, less requirement of skilled labors, massive production with reduced amount of construction waste, better quality and better surface finishing as compared to normal reinforced concrete construction. Buildings are extremely vulnerable to progressive collapses due to the loss of one or more columns. It is, therefore, important to study the potential of precast concrete structures in the Kingdom for progressive collapse to avoid catastrophic events. As precast buildings lack structural continuity and redundancy in the load paths, they are even more susceptible to progressive collapse than cast-in-situ monolithic buildings. The performance of precast concrete system depends on the behavior of connections. The configuration of connections affects the constructability, stability, strength, flexibility, energy dissipation capacity, displacement ductility and residual forces in the structure. Connections alone can dictate the type of precast frame, the limitations of that frame, and the erection progress. Research on progressive collapse of structures was conducted by Peakau and Cui [1], Allen and Schriever [2], Almusallam et al. [3], Elsanadedy et al. [4], Baldridge and Humay [5], Choi and Chang [6] and others.

Many researchers have studied behavior of various types of precast beam-column connections. Shariatmadar and Beydokhti [7] tested three full scale precast beamcolumn connections by considering different detailing, i.e., straight spliced, U-shaped spliced and U-shape spliced with steel plates within connection zone, which was part of a 5story frame under reverse cyclic loading and compared its performance with monolithic connections. Parastesh et al. [8] developed new ductile moment resisting precast beamcolumn connections. They have tested six full-scale interior and exterior precast beam-column connections under cyclic loading and compared their performance with monolithic connections. Performance of precast exterior beam-column connections were experimentally evaluated under reversed cyclic loading [9-14]. In these studies, different designs for precast beam-column connections were adopted such as: connection using dowel bar, dowel bar with cleat angles, cleat angles with single and double stiffeners, tie rod and steel plates, use of cast-in-situ concrete in beam and column, composite connection with welding, bolted connections, etc. In such studies, performance of precast connections was measured on the basis of strength, hysteretic behavior, energy dissipation capacity and ductility behavior. The performance was then compared with their monolithic counterparts.

In this study, the behavior of two different half-scale precast specimens was studied experimentally under middle column removal scenario. These specimens were designed 
to represent the most common types of exiting precast beam-column connections in the Kingdom of Saudi Arabia. One monolithic specimen, which has been designed with continuous top and bottom beam reinforcement, was used as a baseline for comparison with the two precast specimens. The three specimens were tested under middle column removal scenario with the middle column being exposed to high rate dynamic loading at a displacement rate of 100 $\mathrm{mm} / \mathrm{s}$ in order to simulate the progressive collapse in real structures. Performance of test specimens was evaluated and compared on the basis of experimental results.

\section{Experimental Program}

\section{A. Test Matrix}

The test matrix used in this study is summarized in Table 1. The test matrix was designed to study the behavior of existing precast beam-column connections under column removal scenario and compare their behavior to that of monolithic specimen under collapse loading scenario. Two half-scale precast specimens PC-A and PC-B were prepared with beam and column members cast individually and then assembled on test bed as is the norm in the field. The two specimens differed from each other in terms of beamcolumn connections. The concrete dimensions and cross section details for PC-A specimen are shown in Fig. 1(a). For both columns and beams, section sizes of $350 \times 350 \mathrm{~mm}$ were used and the corbels had section dimensions of $250 \times$ $350 \mathrm{~mm}$. Longitudinal reinforcement of beams comprised of $4 \$ 16 \mathrm{~mm}$ rebars on both tension and compression sides and 2 legged $\$ 8 \mathrm{~mm}$ rebars used as stirrups at $100 \mathrm{~mm}$ centerto-center spacing. The longitudinal reinforcement for columns comprised of $8 \phi 16 \mathrm{~mm}$ rebars, and $\phi 8 \mathrm{~mm}$ ties were provided as transverse reinforcement at variable spacing. The height of each column was $1750 \mathrm{~mm}$ and the length of each beam was $2620 \mathrm{~mm}$. The center-to-center distance between columns was kept as $3 \mathrm{~m}$. The PC-A beam-column connection is composed of a corbel rebar being grouted with the beam on both the ends of the beam. The beam had hollow circular pockets of diameter $60 \mathrm{~mm}$ for the corbel rebar to pass through. Before grouting, the beam was made to rest on the corbels and a $20 \mathrm{~mm}$ thick neoprene pad was used to cushion the assembly. Grouting was then done using the locally available material SikaGrout 214, which is a non-shrink modified cementitious grout with shrinkage compensation in both plastic and hardened states. The concrete dimensions and cross section details for PC-B specimen are depicted in Fig. 1(b). It should be noted that precast specimen PC-B differs from PC-A specimen in terms of beam-column connection. Two pockets of diameter $60 \mathrm{~mm}$ were left out at both the beam ends for grouting purposes. In the PC-B specimen, apart from the corbel rebar being grouted with beam, a welded connection was also used. This was accomplished by having an angle section $200 \times 75 \times 10 \mathrm{~mm}$ embedded in the beam and the corbel before casting as shown in Fig. 1(b). A steel plate $150 \times 370 \times 20 \mathrm{~mm}$ was used to rest the beams on the corbel surfaces. After grouting was done using the same SikaGrout 214, the two angles and the steel plate were welded along the edge using a line weld. The center-tocenter distance between the columns was kept the same as 3 $\mathrm{m}$. One other specimen monolithically cast (MC-SMF) was used in the experimental program. This specimen was detailed with continuous top and bottom beam reinforcement. Concrete dimensions and cross section details of specimen MC-SMF are given in Fig. 1(c).

\section{B. Material Properties}

Ready-mix concrete was used for casting the test specimens. The specified compressive strength measured as per the ASTM C39M [15] at the time of the test was 35 $\mathrm{MPa}$. For steel rebars, tensile tests were carried out in accordance with ASTM E8/E8M [16] and the average values for yield strength are 525, 489 and $526 \mathrm{MPa}$ for $\phi 8$ $\mathrm{mm}, \phi 10 \mathrm{~mm}$ and $\phi 16$ steel bars, respectively.

\section{Test Setup and Procedure}

A steel loading frame shown in Fig. 2, which exists in the structural lab of King Saud University was used for testing the connection specimens. The exposure of a building to blast loading may lead to the sudden removal of a column which may lead to the progressive collapse of the structure. This was simulated by releasing the support of the middle test column and applying a dynamic load on that column using an actuator of $1000 \mathrm{kN}$ capacity. The test specimen was placed in position on steel rails, which were anchored to the strong lab floor. The test column was then attached to the actuator. All column bases except that of the test column were affixed to the steel rails.

A high speed data acquisition system was used to collect data at speed of $1 \mathrm{k} / \mathrm{s}$. The individual beam and column members of the specimens were instrumented for recording the state of stress in rebars by using strain gages affixed to the rebars. The center column and beam mid-span displacements were measured using extremely precise laser transducers. The instrumentation program also included measurement of end rotations of the beams using dual-axis inclinometers. The three-dimensional vibration of the specimen was recorded using a tri-axial accelerometer. Fig. 2 depicts the complete instrumentation layout for the precast specimen PC-A.

The support underneath the test column was removed but the test frame was still in undeformed state because of the connection of test column to the actuator. At this stage all sensors were initialized to zero setting. The load on the test column was applied using the actuator in cycles of incremental vertical displacement in each cycle. The unloading of the specimen involved taking the column from displaced position to the initial position. The rate of loading was $100 \mathrm{~mm} / \mathrm{s}$; whereas the unloading was done at a rate of $5 \mathrm{~mm} / \mathrm{s}$. Data recording during the test was done and the results for all specimens were analyzed to study the collapse mechanism of the entire frame specimen as well as individual frame members.

TABLE I. TEST MATRIX

\begin{tabular}{|c|c|c|}
\hline Specimen ID & Type of specimen & $\begin{array}{c}\text { No. of } \\
\text { specimens }\end{array}$ \\
\hline PC - A & Precast type A & 1 \\
\hline PC - B & Precast type B & 1 \\
\hline MC-SMF & $\begin{array}{c}\text { Monolithic with continuous top and } \\
\text { bottom beam reinforcement }\end{array}$ & 1 \\
\hline
\end{tabular}


Proc. of The Fifth Intl. Conf. On Advances in Civil and Structural Engineering - CSE 2016

Copyright $\odot$ Institute of Research Engineers and Doctors, USA .All rights reserved.

ISBN: 978-1-63248-088-0 doi: 10.15224/ 978-1-63248-088-0-21

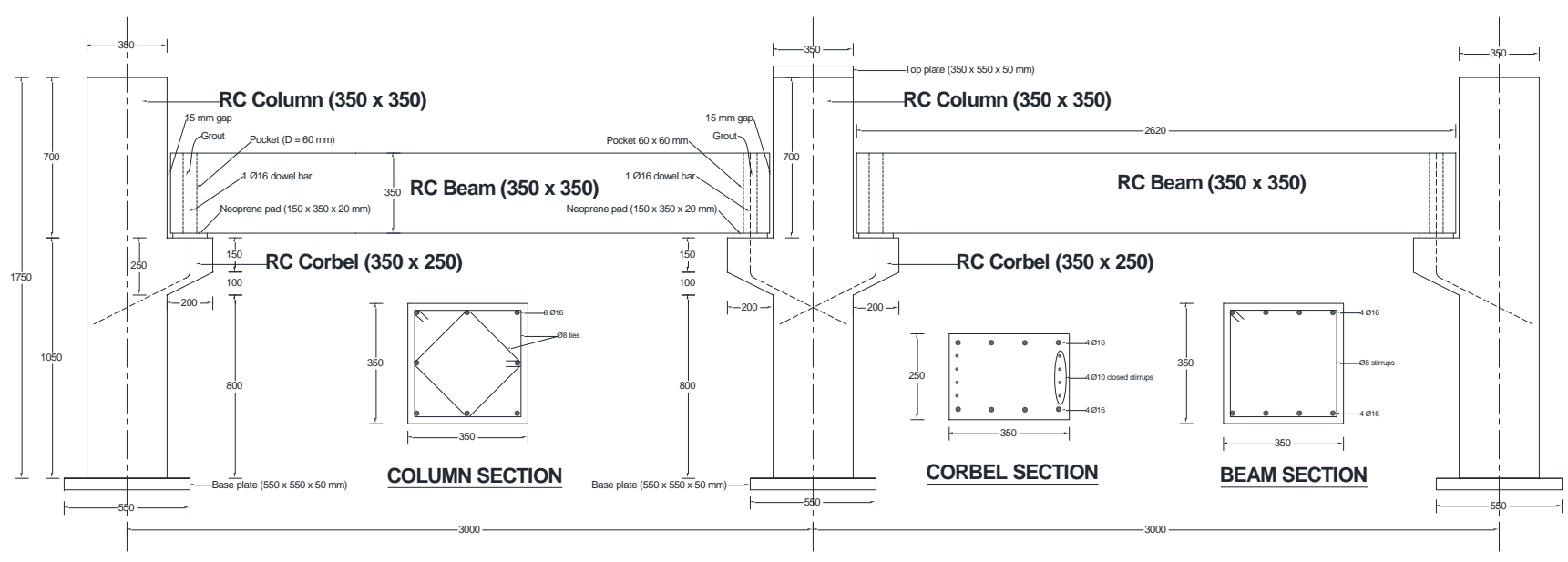

(a) Precast specimen PC-A

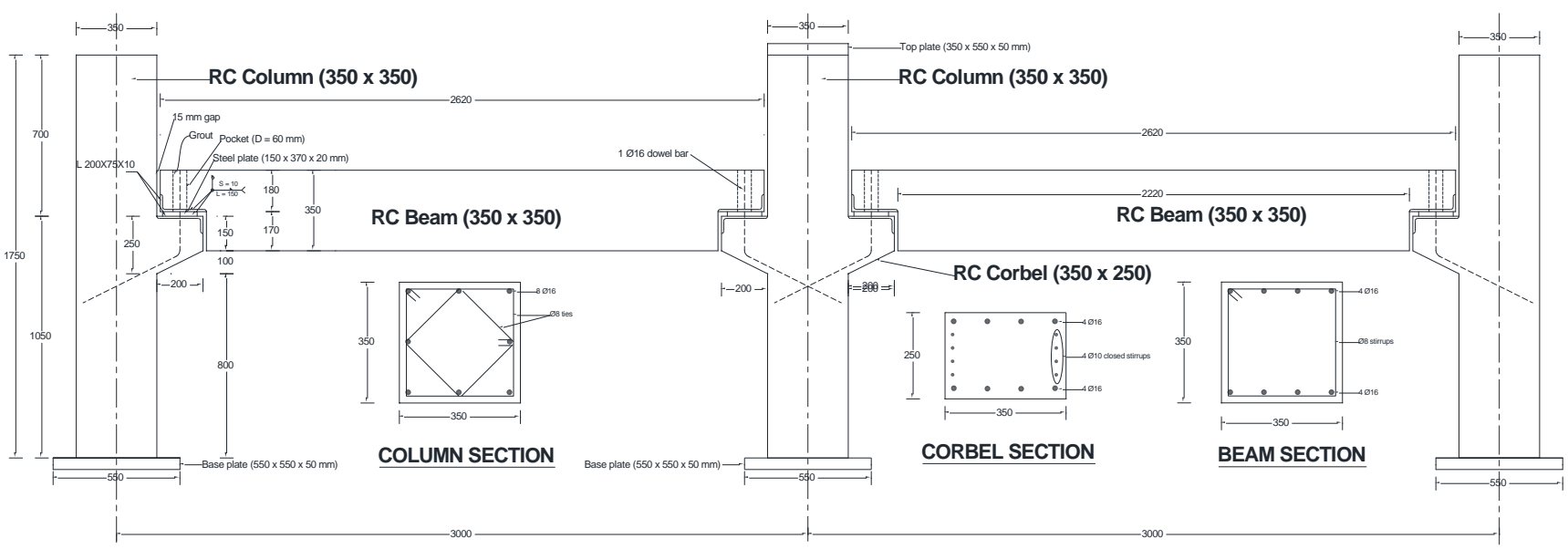

(b) Precast specimen PC-B

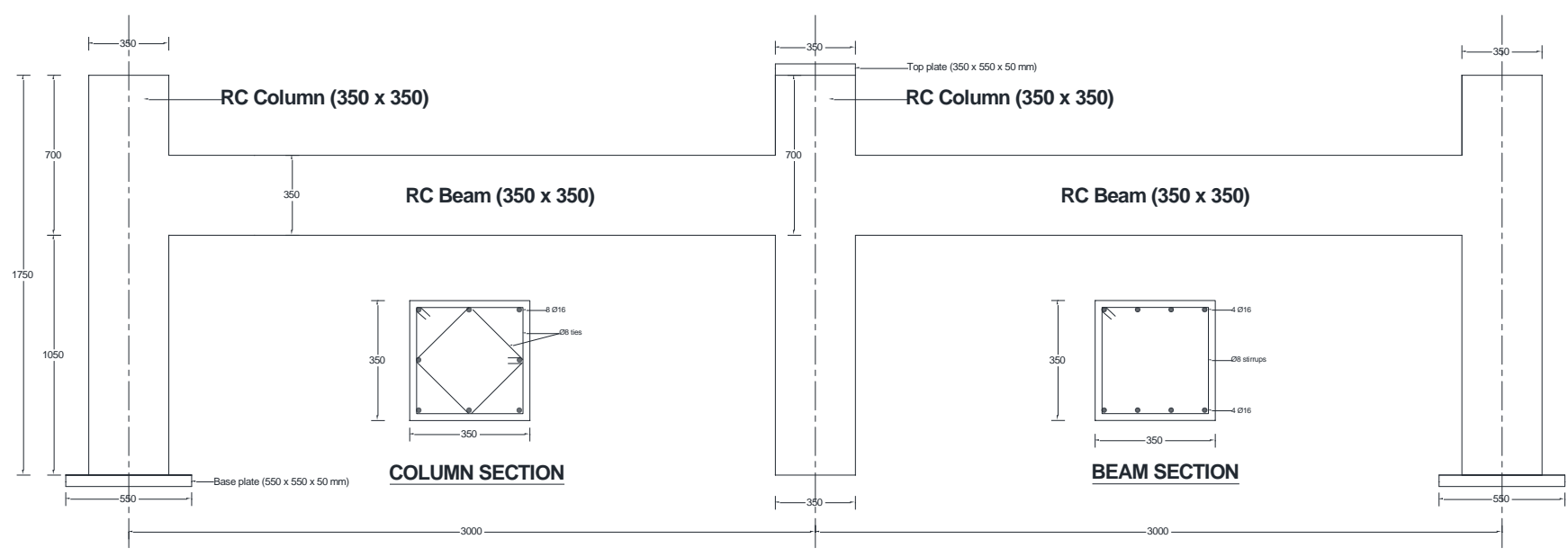

(c) Monolithic specimen MC-SMF

Figure 1. Details of test specimens (Note: All dimensions are in mm) 


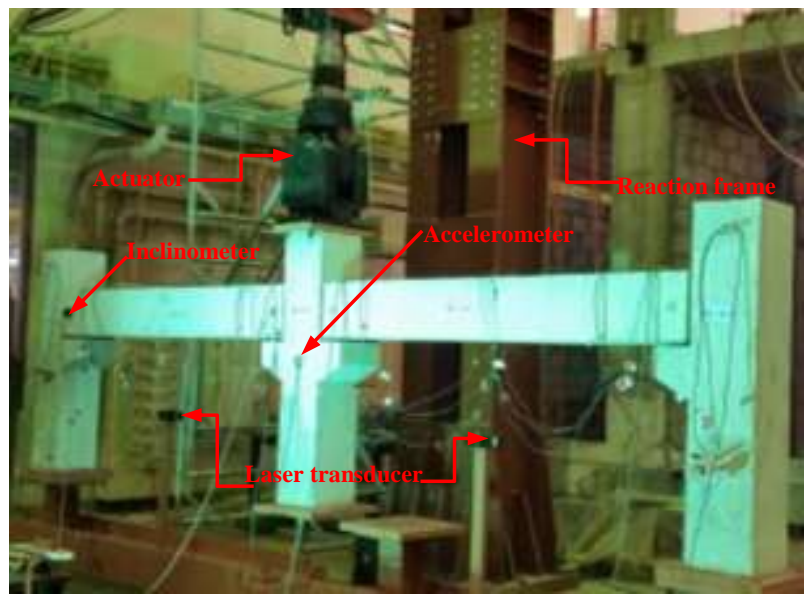

Figure 2. Test setup and instrumentation layout.

\section{Test Results and Discussion}

Table 2 shows a summary of the behavior of test specimens in terms of: (i) peak load without self-weight, (ii) middle column displacement at peak load, (iii) beam midspan deflection at peak load, (iv) load at yielding of main beam bottom steel, (v) middle column displacement at yielding of main beam bottom steel, (vi) middle column displacement at ultimate, (vii) energy ductility, (viii) displacement ductility, and (ix) strain of beam bottom steel bars at peak load. It should be noted that the energy ductility index $\left(\mu_{E}\right)$ shown in Table 2 is calculated as per Emadi and Hashemi [17] from the following formula:

$$
\mu_{E}=\frac{1}{2}\left(\frac{E_{u}}{E_{y}}+1\right)
$$

where $E_{u}$ is the energy of the frame specimen at ultimate state (area under load-displacement curve up to ultimate displacement) and $E_{y}$ is the energy of the frame specimen at first yield of main beam bottom steel (area under loaddisplacement curve up to yield displacement). Final modes of failure at middle beam-column joint are illustrated in Fig. 3 for test frames. Load versus middle column displacement hysteresis and envelopes are presented as shown in Fig. 4 for all test specimens. The curves shown in Fig. 4 do not include the self-weight of the specimen. Comparison of load-displacement envelopes for test frames is shown in Fig. 5. Follows is a discussion of test results for each specimen.

\section{A. Specimen PC-A}

Fig. 4(a) reveals that precast concrete buildings with connection type A is very vulnerable to progressive collapse once the supporting column is lost in an extreme event. The peak load (not including self-weight of frame specimen PCA) was $12.8 \mathrm{kN}$. It was obtained in the 8 th loading cycle corresponding to a target displacement of $200 \mathrm{~mm}$. Due to discontinuity of beam reinforcement at the connection zone, very minor strain of $70 \mu \varepsilon$ (close to zero) was recorded in the beam bottom steel at peak load and hence the specimen has no displacement ductility to dissipate the energy exerted in the system upon sudden column removal as seen in Table 2. As seen in Fig. 3(a) for specimen PC-A, a proper hinge behavior was observed in the specimen which was to be expected. During the test, the left and right beams kept on rotating at their ends until the interior ends came in touch with the middle column, and the ultimate mode of failure was due to crushing of concrete at the location of interior beam-column connection as seen in Fig. 3(a). Other than this, no other damage was observed in any members of the frame.

\section{B. Specimen $\boldsymbol{P C}-\boldsymbol{B}$}

It is clear from Figs. 4 and 5 that the precast connection type B is better than connection type A in terms of its resistance to progressive collapse when subjected to sudden removal of column as a result of unexpected loading scenarios. For the precast specimen PC-B, the peak load (not including self-weight of the frame) was $23.4 \mathrm{kN}$. It was obtained in the 10th loading cycle corresponding to a target displacement of $300 \mathrm{~mm}$ as shown in Fig. 4(b). As shown in Table 2, very small strain of $620 \mu \varepsilon$ was measured in the beam bottom steel at peak load. Therefore, the specimen has no displacement ductility to dissipate the energy input in the system upon sudden column removal, which makes it vulnerable to progressive collapse. Fig. 3(b) presents the final failure mode for the PC-B frame at the interior beamcolumn connection. As seen from the figure, a proper hinge behavior was noticed and the left and right beams kept on rotating until failure occurred due to debonding of steel plates of the corbels near the interior column. Some minor cracks were also formed in the corbels of the middle column. For the end corbels, diagonal splitting was observed and it was consistent for both the ends.

\section{Specimen MC-SMF}

From the load-displacement comparison presented in Fig. 5 , it is clear that the monolithic specimen MC-SMF (with continuous top and bottom beam reinforcement) has excellent performance compared with the two precast specimens PC-A and PC-B. The peak load (not including self-weight) resisted by specimen MC-SMF was $228 \mathrm{kN}$ which is about 17.8 and 9.7 times of that for specimens PC$\mathrm{A}$ and PC-B, respectively. This peak load was obtained in the 8th loading cycle corresponding to a target displacement of $200 \mathrm{~mm}$ as shown in Fig. 4(c). At peak load, and as shown in Table 2, a tensile strain of $94900 \mu \varepsilon$ (about 36 times the yield strain) was recorded in the bottom steel bars of the beam. In addition, and as depicted from Table 2, displacement and energy ductility ratios of specimen MCSMF were very high. The excellent performance of the monolithic specimen MC-SMF is expected due to the continuity of the beam reinforcement and hence the redundancies in the load paths. Fig. 3(c) depicts the final failure mode for the MC-SMF frame at the middle beamcolumn joint. Failure of specimen MC-SMF occurred around the middle column due to plastic hinge formation in the beam area near the connection zone. As seen in Fig. 3(c), a plastic hinge was formed near the middle joint due to large plastic strains in the bottom steel bars of the beam beyond their yield state (indicated by wide flexural cracks) accompanied with concrete crushing in the compression zone. As seen from Fig. 3(c), failure of beam was not purely symmetric on both sides of the middle column. 
Proc. of The Fifth Intl. Conf. On Advances in Civil and Structural Engineering - CSE 2016

Copyright $(\odot$ Institute of Research Engineers and Doctors, USA .All rights reserved.

ISBN: 978-1-63248-088-0 doi: 10.15224/ 978-1-63248-088-0-21

TABLE II. COMPARISON OF TEST RESULTS FOR SPECIMENS*

\begin{tabular}{|c|c|c|c|c|c|c|c|c|c|}
\hline Specimen ID & $P_{u}(\mathbf{k N})$ & $\Delta_{u, c}(\mathbf{m m})$ & $\Delta_{u, b}(\mathbf{m m})$ & $P_{y}(\mathbf{k N})$ & $\Delta_{y}(\mathbf{m m})$ & $\Delta_{u}(\mathbf{m m})$ & $\mu_{E}$ & $\mu_{\Delta}$ & $\varepsilon_{s u, b}(\mu \varepsilon)$ \\
\hline PC-A & 12.8 & 145 & 66 & No steel yielding & No steel yielding & 265 & - & - & 70 \\
\hline PC-B & 23.4 & 250 & 106 & No steel yielding & No steel yielding & 284 & - & - & 620 \\
\hline MC-SMF & 228 & 144 & 65 & 145 & 25.6 & 269 & 13.8 & 10.5 & 94900 \\
\hline
\end{tabular}

$* P_{u}=$ peak load without self-weight, $\Delta_{u, c}=$ middle column displacement at peak load, $\Delta_{u, b}=$ beam mid-span deflection at peak load, $P_{y}=$ load at yielding of bottom beam steel, $\Delta_{y}=$ middle column displacement at yielding of bottom beam steel, $\Delta_{u}=$ middle column displacement at ultimate, $\mu_{E}=$ energy ductility, $\mu_{\Delta}=$ displacement ductility $=\Delta_{u} / \Delta_{y}, \varepsilon_{s u, b}=$ strain of beam bottom steel bars at peak load.

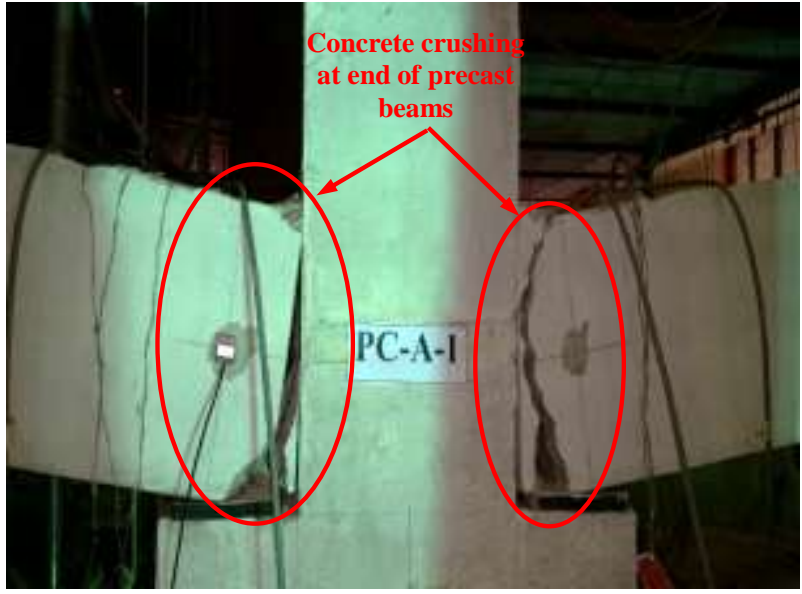

(a) Precast specimen PC-A

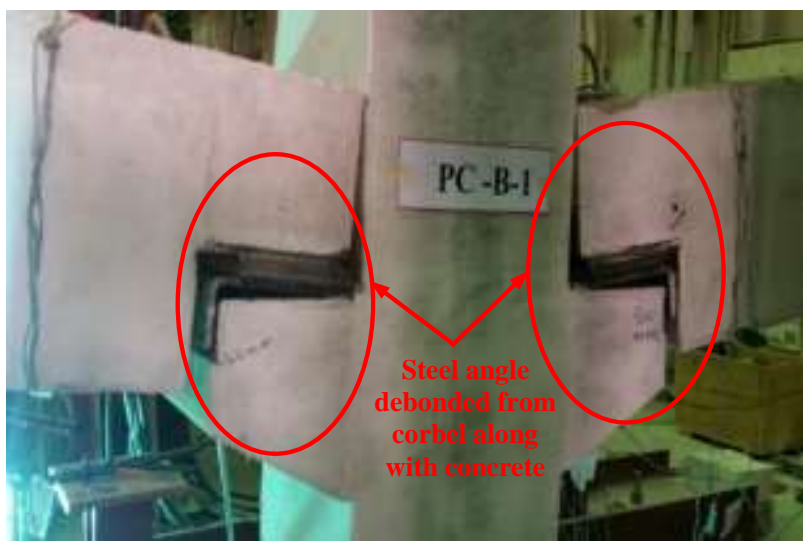

(b) Precast specimen PC-B

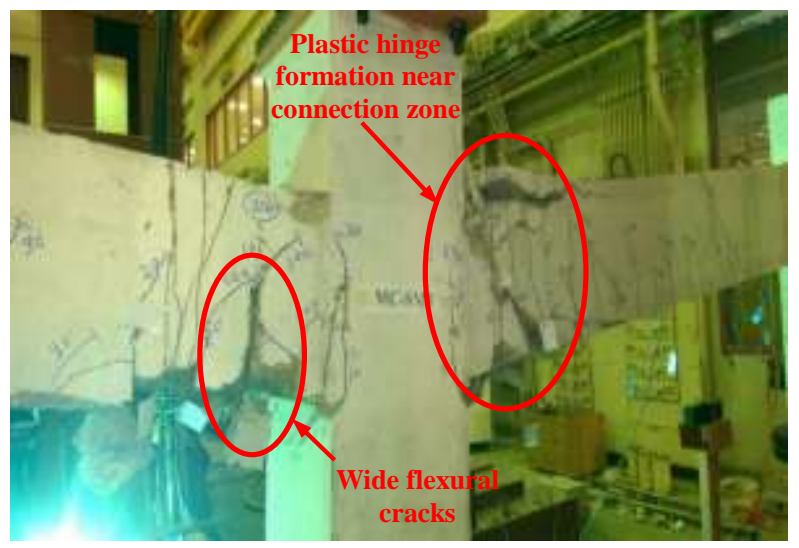

(c) Monolithic specimen MC-SMF

Figure 3. Failure mode of test specimens at middle joint.

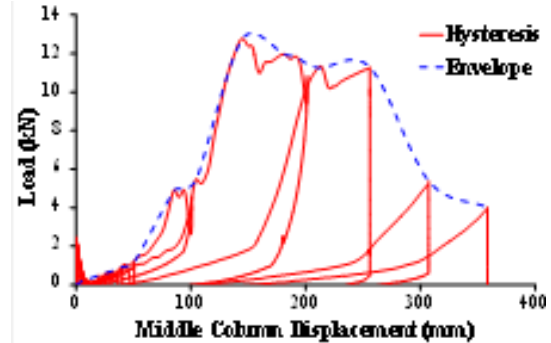

(a) Precast specimen PC-A

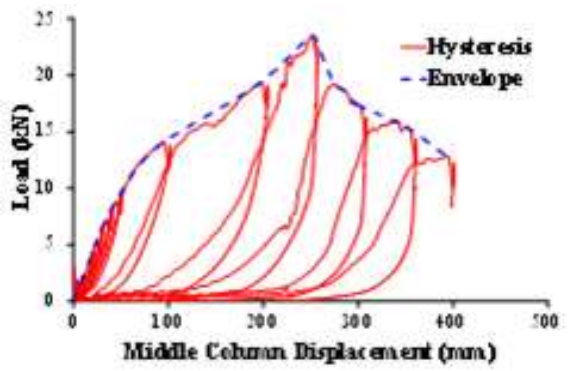

(b) Precast specimen PC-B

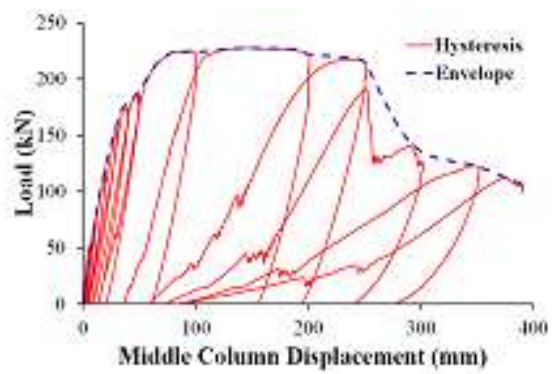

(c) Monolithic specimen MC-SMF

Figure 4. Load-displacement hysteresis for test specimens.

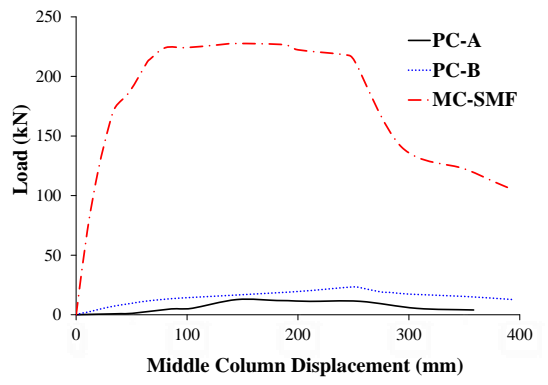

Figure 5. Load-displacement envelope comparison for test specimens. 


\section{Conclusions}

The major conclusions derived from this study can be summarized as follows:

- Precast connection type $\mathrm{B}$ is relatively better than connection type $\mathrm{A}$ in terms of its resistance to progressive collapse. The peak load of precast specimen PC-B was about 1.8 times of that for specimen PC-A.

- From the comparison of peak load, monolithic specimen MC-SMF with continuous top and bottom beam reinforcement had a dramatic increase in ultimate load compared to other two specimens, as load carrying capacity of monolithic specimen was 17.8 and 9.7 of that for precast specimens PC-A and PC-B, respectively.

- The displacement and energy ductility ratios of specimen MC-SMF were very large. However, precast connection types A and B have no ductility to dissipate the energy exerted in the system upon column removal scenario due to extreme loading conditions.

- The two tested types of precast connections were found to have a very high potential of progressive collapse due to lack of their structural continuity and hence absence of redundancies in the load paths.

\section{Acknowledgment}

This work is based on the Project funded by the National Plan for Science, Technology and Innovation (MAARIFAH), King Abdulaziz City for Science and Technology, Kingdom of Saudi Arabia, Award Number (12BUI2620-02).

\section{References}

[1] O. A. Peakau, and Y. Cui, "Progressive collapse simulation of precast panel shear walls during earthquakes," Comput Struct, 84:400-412, 2006.

[2] D. E. Allen, and W. R. Schriever, Progressive Collapse, Abnormal Load, and Building Codes, Structural Failure: Modes, Causes, Responsibilities. Proceedings American Society of Civil Engineers, New York, 1972.

[3] T. H. Almusallam, H. M. Elsanadedy, H. Abbas, S. H. Alsayed, and Y. A. Al-Salloum, "Progressive collapse analysis of a RC building subjected to blast loads," Struct Eng Mech, Techno Press, 36(3):301319, 2010.

[4] H. M. Elsanadedy, T. H. Almusallam, Y. R. Alharbi, and Y. A. AlSalloum, "Progressive collapse potential of a typical steel building due to blast attacks," J Constr Steel Res, 101:143-157, 2014.

[5] S. M. Baldridge, and F. K. Humay, Reinforced Concrete and Secure Buildings: Progressive Collapse. The Structural Bulletin Series, Concrete Reinforcing Steel Institute, No. 2, 2004.

[6] J. Choi, and D. Chang, "Prevention of progressive collapse for building structures to member disappearance by accidental actions," J Loss Prevent Proc, 22:1016-1019, 2009.

[7] H. Shariatmadar, and E. Z. Beydokhti "Experimental investigation of precast concrete beam to column connections subjected to reversed cyclic loads," In: Proc of the 6th int conf on seismology and earth engineering, Tehran, Iran, 16-18 May 2011, pp 1-9.
[8] H. Parastesh, I. Hajirasouliha, and R. Ramezani, "A new ductile moment-resisting connection for precast concrete frames in seismic regions: an experimental investigation," Eng Struct, 70:144-157, 2014.

[9] R. Vidjeapriya, and K. P. Jaya, "Experimental investigation of precast concrete beam-column wet connection under cyclic loading," In: Proc of the structural engineering convention (SEC), Surat, Gujarat, India, 19-21 Dec 2012, pp 287-292.

[10] R. Vidjeapriya, and K. P. Jaya, "Experimental study on two simple mechanical precast beam column connections under reverse cyclic loading," J Perform Constr Facil, 27:402-414, 2013.

[11] R. Vidjeapriya, and K. P. Jaya, "Behaviour of precast beam-column mechanical connections under cyclic loading," Asian J Civil Eng (Build Hous), 13:233-245, 2014.

[12] A. Rahman et al, "Hybrid beam-to-column connections for precast concrete frames," In: Proc of the 6th Asia-Pacific structural engineering construction conference, Kuala Lumpur, Malaysia, 5-6 Sept 2006, pp A281-A290

[13] O. Ertas, S. Ozden, and T. Ozturan, "Ductile connections in precast concrete moment resisting frames," PCI J, 5:2-12, 2006.

[14] M. K. Joshi, C. V. Murty, and M. P. Jaisingh, "Cyclic behaviour of precast RC connections," Indian Concr J, 79:43-50, 2005.

[15] ASTM, Standard Test Method for Compressive Strength of Cylindrical Concrete Specimens. ASTM C39/C39M, American Society for Testing and Materials, West Conshohocken, PA, USA, 2010 .

[16] ASTM, Standard Test Methods for Tension Testing of Metallic Materials. ASTM E8/E8M, American Society for Testing and Materials, West Conshohocken, PA, USA, 2009.

[17] J. Emadi, and S. H. Hashemi, "Flexural study of high strength RC beams strengthened with CFRP plates," World Academy of Science, Engineering and Technology, 78:380-384, 2011.

\section{About Author (s):}

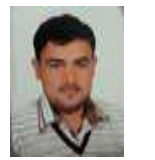

Mohammed A. Alrubaidi. He is a graduate student, Dept. of Civil Engineering, King Saud Univ., Riyadh, Saudi Arabia. His research interests include behavior of precast concrete buildings under extreme loading conditions.

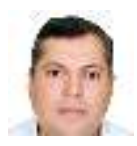

Hussein M. Elsanadedy. He is associate professor, Dept. of Civil Engineering, King Saud Univ., Riyadh, Saudi Arabia (on leave from Helwan University, Cairo, Egypt). He received his B.Sc. and M.Sc. from Helwan University, Cairo, Egypt and his Ph.D. in Structural Engineering from the University of California, Irvine, Calif., USA in 2002. His research interests include: rehabilitation of RC structures using FRP and TRM composites; numerical modeling of steel and concrete structures; failure analysis and damage assessment of buildings and bridges; in addition to behavior of steel and concrete buildings under extreme loading conditions. 